\title{
Correction to: Computational limitations of affine automata and generalized affine automata
}

\author{
Mika Hirvensalo ${ }^{1,2}$ (1) Etienne Moutot $^{3}$ (D) - Abuzer Yakaryılmaz ${ }^{1,4}$
}

Published online: 31 March 2021

(C) Springer Nature B.V. 2021

\section{Correction to: Natural Computing}

https://doi.org/10.1007/s11047-020-09815-1

In the original publication of the article, unfortunately, the corrections provided were missed for affiliations, equations and sentences. The original article has been updated with the corrections.

The original article has been corrected.

Publisher's Note Springer Nature remains neutral with regard to jurisdictional claims in published maps and institutional affiliations.

The original article can be found online at https:// doi.org/10.1007/s11047-020-09815-1.

Mika Hirvensalo

mikhirve@utu.fi

Etienne Moutot

etienne.moutot@ens-lyon.org

Abuzer Yakaryılmaz

abuzer@lu.lv

1 Department of Mathematics and Statistics, University of Turku, FI-20014 Turku, Finland

2 Turku Centre for Computer Science (TUCS), Turku, Finland

3 Aix-Marseille Univ., Toulon Univ., CNRS, LIS, Marseille, France

4 Center for Quantum Computer Science, Faculty of Computing, University of Latvia, Riga, Latvia 